\title{
Prevalence of Abdominal Obesity and Excess Weight among Portuguese Children and Why Abdominal Obesity Should Be Included in Clinical Practice
}

\section{Prevalência de Obesidade Abdominal e Excesso Ponderal em Crianças Portuguesas e a Importância de Incluir a Obesidade Abdominal nas Consultas Médicas}

\author{
Daniela RODRIGUES $\square^{1,2}$, Cristina PADEZ ${ }^{1,2}$, Aristides M. MACHADO-RODRIGUES ${ }^{1,2,3}$ \\ Acta Med Port 2018 Mar;31(3):159-164 - https://doi.org/10.20344/amp.9000
}

\section{ABSTRACT}

Introduction: Central adiposity in children has increased to a higher degree than general adiposity however it is not a routine measurement in clinical practice. We aimed to estimate the prevalence of overweight, obesity, and abdominal fat distribution and observe the prevalence of abdominal obesity among non-obese 6-10-year-old children.

Material and Methods: Weight, height, and waist circumference were measured in a sample of 793 children (408 girls). International Obesity Task Force cut-offs were used to define overweight and obesity. Abdominal obesity was defined as waist-to-height ratio $\geq$ 0.50 . Chi-square tests were used to observe the prevalence of the obesity indicators among boys and girls, and the relation between International Obesity Task Force cut-offs and abdominal obesity.

Results: The prevalence of overweight, including obesity among children was $21.9 \%(18.9-25.0), 6.1 \%(4.2-8.0)$ were obese and $21.9 \%(18.6-25.0)$ had a waist-to-height ratio $\geq 0.50$. Girls had significantly higher prevalence of overweight, including obesity compared to boys $\left(\chi^{2}=4.59, p=0.03\right)$, but no differences were found for abdominal obesity according to children's gender $\left(\chi^{2}=3.32\right.$, $p=0.07)$. A proportion of normal $(8.2 \% ; 5.9-10.6)$ and overweight children $(59.5 \% ; 50.9-69.0)$ were abdominally obese.

Discussion: The prevalence of general and abdominal obesity in children living in central Portugal is of concern. Many children with abdominal obesity would not be considered obese with the International Obesity Task Force cut-off points.

Conclusion: A high proportion of abdominal obesity was observed in children with normal weight or overweight, suggesting that waistto-height ratio should be included in routine clinical practice and might be particularly useful to assess the health status of the child.

Keywords: Adiposity; Body Mass Index; Child; Obesity, Abdominal; Pediatric Obesity; Portugal

\section{RESUMO}

Introdução: A obesidade abdominal em crianças tem aumentado a ritmo alarmante, mas esse indicador não é avaliado em consultas médicas de rotina. Este estudo pretende avaliar a prevalência de excesso ponderal e obesidade abdominal e a relação entre os dois indicadores de obesidade, em crianças dos 6 aos 10 anos.

Material e Métodos: Numa amostra de 793 crianças (408 raparigas) foram medidos o peso, altura e a circunferência abdominal. Os critérios da International Obesity Task Force foram usados para definir o excesso ponderal e obesidade. Obesidade abdominal foi estimada como a relação cintura/altura $\geq 0,50$. Testes estatísticos foram usados para testar os objetivos supramencionados.

Resultados: A prevalência de excesso ponderal, incluindo obesidade foi de $21,9 \%(18,9-25,0)$, sendo significativamente mais elevada nas raparigas do que nos rapazes $\left(\chi^{2}=4,59, p=0,03\right)$. A prevalência de obesidade abdominal foi de $21,9 \%(18,6-25,0)$, sem diferenças significativas em relação ao género $\left(\chi^{2}=3,32, p=0,07\right)$. Verificámos que $8,2 \%(5,9-10,6)$ das crianças com peso normal e $59,5 \%(50,9-69,0)$ de crianças com excesso ponderal tinham obesidade abdominal.

Discussão: A prevalência de obesidade, incluindo abdominal, é elevada nas crianças portuguesas, mas parece ter estabilizado nos últimos anos. Várias crianças com obesidade abdominal foram consideradas não obesas segundo os indicadores da International Obesity Task Force.

Conclusão: Dado que várias crianças não obesas apresentam valores elevados de obesidade abdominal, a medição da relação cintura/altura deve ser incluída em consultas médicas de rotina, de modo a permitir uma melhor avaliação do estado de saúde da criança.

Palavras-chave: Adiposidade; Criança; Índice de Massa Corporal; Obesidade Abdominal; Obesidade Pediátrica; Portugal

\section{INTRODUCTION}

The childhood obesity epidemic is one of the greatest current challenges for health policy, including in Portugal. ${ }^{1-5}$ The health consequences of overweight, obesity, and abdominal obesity during childhood are strongly associated with risk factors for a number of medical conditions such as cardiovascular diseases, diabetes, and cancer. ${ }^{6-9}$ Previous findings shown that abdominal obesity is a better predictor of cardiovascular disease and metabolic risk factors in children than body mass index (BMI) and generalized obesity, ${ }^{10,11}$ Also, childhood obesity is an important predictor of adult obesity and related comorbidities. . $^{72}$

Portugal has one of the highest childhood obesity rates

1. CIAS-Centro de Investigação em Antropologia e Saúde. Coimbra. Portugal

2. Departamento de Ciências da Vida. Faculdade de Ciências e Tecnologia. Universidade de Coimbra. Coimbra. Portugal.

3. Escola Superior de Educação. Instituto Politécnico de Viseu. Viseu. Portugal.

$\triangle$ Autor correspondente: Daniela Rodrigues. rodrigues1323@gmail.com

Recebido: 24 de março de 2017 - Aceite: 20 de fevereiro de 2018 | Copyright @ Ordem dos Médicos 2018 
in Europe ${ }^{13}$ and previous studies reported a tendency for weight increase along the last thirty decades. ${ }^{3}$ In a study from 2004 using a sample of 7 - 9-year-old children, $29.4 \%$ of boys and $33.7 \%$ of girls were overweight or obese. ${ }^{3}$ Later, a study from 2008 found that $40.5 \%$ of boys and $35.5 \%$ of girls (aged $6-9$ ) were considered overweight (including obese). ${ }^{14}$ Studies continued to show that around one-third of the Portuguese children have excess weight, which can have serious adverse results on their health. ${ }^{4,15-17}$

A number of methodologies are used to define children's nutritional status, like the cut-off points from the World Health Organization $(\mathrm{WHO})^{18}$ and the ones from the International Obesity Task Force (IOTF). ${ }^{19}$ Previous works have concluded that the WHO criteria seem better to detect obesity and overweight in children from a population although, to confirm the disease, namely in a clinical context, the IOTF criterion seems to be more accurate to define obesity and has become the most commonly method used among Portuguese samples. ${ }^{20}$

Recently, the waist-to-height ratio ( $\mathrm{WHtR}$ ) emerged as a good predictor for abdominal obesity and cardiovascular risk factors. ${ }^{10}$ Secular trends of BMI and waist circumference (WC) indicate greater increase in abdominal fat compared to general adiposity.21,22 Furthermore, previous studies have found that some abdominally obese youth were classified as normal weight or overweight using BMI cutoff points ${ }^{23,24}$ which is worrying since a higher cardiometabolic risk was found among normal and overweight children with abdominal obesity compared to overweight children without excessive abdominal fat accumulation. ${ }^{25}$ However, fat distribution is not routinely measured in clinical practice, with most national and international guidelines recommending the use of percentiles based on height and weight to classify children at cardio-metabolic risk. ${ }^{26,27}$ This study aimed to estimate the prevalence of overweight, obesity and abdominal obesity, as well as to analyze the proportion of abdominal obesity in normal and overweight 6-10-year-old children from the central region of Portugal.

\section{MATERIAL AND METHODS}

\section{Sampling and procedure}

This paper is part of a larger cross-sectional study that examines the association of social, cultural and physical environmental factors with participation in extracurricular sport and obesity indicators in children living in central Portugal. ${ }^{28,29}$ The study protocol was approved by the Portuguese Commission for Data Protection which requires anonymity and no transmissibility of data, corroborated by the Direcção Geral de Inovação e Desenvolvimento Curricular (Portuguese General Directorate of the Ministry of Education).

Parental written consent on behalf of each participant was distributed in the largest public elementary schools from the city of Coimbra and the village of Lousã, both situated in the central region of Portugal. All the $1^{\text {st }}$-to- $4^{\text {th }}$ grade children attending those schools were intended to participate.
A total of 1369 consents were initially distributed. Parents were informed that they had one week to return the consent forms completely filled if they wanted to participate in the study.

Parents who reported that their child had a health condition that would hinder their participation in sport activities were not included in the main project. A total of 834 parents and respective children participated in the project ${ }^{28}$ but the anthropometric measures were only collected in 793 children. Differences between the number of consents and children included in the study are due to children not being at school during data collection, not feeling well to participate, or simple refusing to be measured.

The sample included participants from a range of socioeconomic backgrounds and from different residential areas as described elsewhere ${ }^{28,29}$ and evaluates slightly more than $13 \%$ of all the targeted population, since the latest data reported a total of 5992 children enrolled in the $1^{\text {st }} 4^{\text {th }}$ grade in the areas where the present data were collected. ${ }^{30}$

\section{Anthropometry}

The anthropometric variables were gathered in schools, during the morning, by the first author and a small group of well trained investigators. An initial presentation intended to make participants feel more at ease with the professionals while the measurement procedure was explained. Also, children were informed that they could withdraw from the study at any stage. Height $(\mathrm{cm})$ and weight $(\mathrm{kg})$ were measured with participants dressed in lightweight clothing and without shoes, using an electronic scale (to the nearest $100 \mathrm{~g}$ ) and a portable stadiometer (to the nearest $5 \mathrm{~mm}$ ). Waist circumference $(\mathrm{cm})$ was measured with a metric tape (to the nearest $5 \mathrm{~mm}$ ), midway between the lowest rib and the iliac crest to the nearest $0.1 \mathrm{~cm}$ after inhalation and exhalation. BMI was calculated and the definition of overweight and obesity were defined using the IOTF cutoffs. ${ }^{19} \mathrm{WHtR}$ was calculated as the ratio of waist and height using the cut-off value of $\geq 0.5$. $^{31}$ The study was conducted from April to mid-June 2013 and 2014, avoiding the effects of winter and seasonality on children's sport participation and physical activity behaviors.

\section{Statistical analysis}

Normal distribution of the data was evaluated. After that student's $t$-tests (following the central limit theorem) were used to test continuous variables (anthropometric measures) according to children's gender and chi-square tests were used to observe possible statistical differences in the prevalence of overweight/obesity and abdominal obesity between genders. Crosstabs were used to observe the proportion of normal and overweight children with elevated levels of abdominal obesity. The level of significance was set at $5 \%$. All statistical analyses were performed using the Statistical Package for the Social Sciences (SPSS v.23; SPSS an IBM Company, Chicago, IL). 


\section{RESULTS}

A total of 408 girls $(51.45 \%)$ and 385 boys were measured. The mean age of the sample was $8.05 \pm 1.21$ (range 6-to-10 years). Mean values of the anthropometric measures are shown in Table 1. No statistical differences were found in height, weight, WC, BMI, and WHtR according to children's gender.

The prevalence of overweight (including obesity) found in the sample was $21.9 \%$ (18.9 - 25.0), with $15.9 \%$ (13.1 18.5) of children classified as overweight and $6.1 \%(4.2-8.0)$ as obese. Girls presented higher prevalence of all obesity indicators compared to boys, but only in the prevalence of overweight, including obesity the results were statistically significant $\left(\chi^{2}=4.59, p=0.03\right)$, with $25.0 \%(21.7-30.9)$ of the girls and $18.7 \%$ (16.5 - 25.1) of the boys having excess weight (Table 2). No significant difference was found in the prevalence of overweight and obesity $(p=0.21)$, and abdominal obesity $(p=0.42)$ according to children's age (data not shown in tables).

Prevalence of abdominal obesity (WHtR $\geq 0.5)$ was higher than general obesity based on IOTF definition (Table 2). A proportion of children that were classified as having normal weight $(8.2 \% ; 5.9-10.6)$ or being overweight $(59.5 \%$; 50.9 - 69.0) using the IOTF cut-offs were abdominally obese (Table 3). More normal weight and overweight girls, compared to boys, were abdominally obese.

\section{DISCUSSION}

We found that overweight, obesity, and abdominal obesity are common among Portuguese children living in central Portugal, particularly among girls. However, comparing our results with previous national studies among children of the same age range, we observe a possible decrease or stabilization of the prevalence in overweight and obesity. Data from 2000, showed that the prevalence of excess weight was around $47.3 \%$ and $35.5 \%$ for 9 and 10 year-old children. ${ }^{32} \mathrm{~A}$ study published in 2005 reported a prevalence of overweight and obesity of $20.3 \%$ and $11.3 \%$, respectively, in 7 - 9.5-year-old Portuguese children. ${ }^{33}$ Later, in $2008,37.9 \%$ children living in Portugal were classified as overweight (including obese) and $15.3 \%$ obese, ${ }^{14}$ and a study carried in 2009/2010 among 9 - 10-year-old Portuguese children observed that $31 \%$ of the children were overweight/obese. ${ }^{34}$ More recently, data from the central region of Portugal, observed that among 6 - 12-year-old children, $22.3 \%$ were considered overweight and $10.7 \%$ as obese. ${ }^{17}$ Those results, compared with the prevalence found in this study for overweight (15.9\%), obesity (6.1\%) and overweight including obesity $(21.9 \%)$, suggest that the prevalence of overweight and obesity may have been decreasing in the last few years. This possible plateau in the prevalence of overweight/obesity in Portugal was already suggested by Gomes and colleagues, ${ }^{4}$ and has been found

Table 1 - Characteristics of the sample

\begin{tabular}{|c|c|c|c|c|c|}
\hline Measures & All sample $(n=793)$ & Girls $(n=408)$ & Boys $(n=385)$ & $t$ & $p$ value \\
\hline Height (cm) & $128.25(8.73)$ & $128.21(9.01)$ & $128.29(8.44)$ & -0.13 & 0.90 \\
\hline Weight (kg) & $28.35(6.57)$ & $28.54(6.86)$ & $28.15(6.25)$ & 0.83 & 0.41 \\
\hline WC $(\mathrm{cm})$ & $60.79(6.79)$ & $60.92(6.86)$ & $60.65(6.71)$ & 0.54 & 0.59 \\
\hline WHtR & $0.47(0.04)$ & $0.47(0.04)$ & $0.47(0.04)$ & 0.54 & 0.59 \\
\hline BMI $\left(\mathrm{kg} / \mathrm{m}^{2}\right)$ & $17.03(2.25)$ & $17.13(2.36)$ & $16.92(2.13)$ & 1.31 & 0.19 \\
\hline BMI z-score & $0.50(0.99)$ & $0.49(0.99)$ & $0.52(1.00)$ & -0.46 & 0.65 \\
\hline
\end{tabular}

Data are presented as mean (standard deviation).

BMI: body mass index: BMI z-score: body mass index standard deviation score; WC: waist circumference; WHtR: waist-to-height ratio; $p$ value calculated by Student's $t$-test

Table 2 - Prevalence of overweight, obesity, and abdominal obesity in children from the central region of Portugal

\begin{tabular}{|c|c|c|c|c|c|c|c|c|c|}
\hline \multirow{2}{*}{ Obesity indicators } & \multicolumn{2}{|l|}{ All sample } & \multicolumn{2}{|l|}{ Girls } & \multicolumn{2}{|l|}{ Boys } & \multicolumn{3}{|c|}{ Chi-square } \\
\hline & $\%(95 \% \mathrm{Cl})$ & $\mathrm{n}$ & $\%(95 \% \mathrm{Cl})$ & $\mathrm{n}$ & $\%(95 \% \mathrm{Cl})$ & $\mathrm{n}$ & $\chi^{2}$ & $p$ value & Cramer's V \\
\hline Overweight & $15.9(13.1-18.5)$ & 126 & $17.4(13.4-21.8)$ & 71 & $14.3(10.7-18.7)$ & 55 & 1.56 & 0.41 & 0.06 \\
\hline Obesity & $6.1(4.2-8.0)$ & 48 & $7.6(5.1-10.4)$ & 31 & $4.4(2.4-6.8)$ & 17 & 2.01 & 0.32 & 0.06 \\
\hline Overweight/obese & $21.9(18.9-25.0)$ & 174 & $25.0(21.7-30.9)$ & 102 & $18.7(16.5-25.1)$ & 72 & 4.59 & 0.03 & 0.09 \\
\hline $\mathrm{WH} t \mathrm{t} \geq 0.5$ & $21.9(18.6-25.0)$ & 174 & $24.7(19.9-29.2)$ & 101 & $19.0(15.1-23.4)$ & 73 & 3.32 & 0.07 & 0.07 \\
\hline
\end{tabular}

Results presented as percentage (95\% confidence interval), $\mathrm{n}$, and chi-squared tests (including Cramer's $\mathrm{V}$ ).

WHtR: waist-to-height ratio; BMI: body mass index; overweight and obesity are defined according to the IOTF cut-offs of BMI

Table 3 - Prevalence of abdominal obesity according to BMI categories

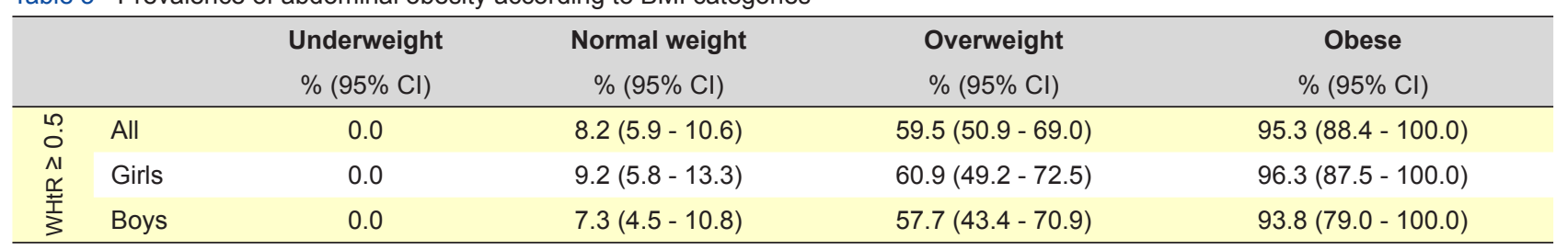

Results presented as percentage (95\% confidence interval); prevalence calculated using the International Obesity Task Force (IOTF) reference values. WHtR: waist-to-height ratio 
in several European countries. ${ }^{35}$

We found a higher prevalence of overweight (including obesity) in girls $(25.0 \%)$ compared to boys $(18.7 \%)(p=0.03)$. However, those differences did not remain significant when comparing overweight and obesity separately. Differences among genders have been observed in previous studies but are not consistent with some registering higher levels of overweight/obesity among girls than boys ${ }^{3,34}$ while others found the inverse..$^{15,17,36}$ These disparities between studies may be due to differences in age groups or lifestyle habits (e.g., physical activity and diet).

Data for abdominal obesity in Portuguese school-aged children are not common but comparing with previous studies among children living in the same region, we found that the prevalence has remained stable from $23.6 \%$ in $2012^{17}$ to $21.9 \%$ in the present study. Also, present rates are lower than the ones found in Greece, where approximately one fourth of boys and girls (aged 7) and one third of 9-year-old children had abdominal obesity. ${ }^{37}$ In contrast, the prevalence of abdominal obesity was only $8.2 \%$ and $8.9 \%$ in children living in Sweden and Norway, respectively. ${ }^{38,39}$ A slight tendency was found in girls having higher risk of abdominal obesity than boys $(24.7 \%$ and $19.0 \%$, respectively; $p$ $=0.07$ ), which is in line with the findings reported in the NHANES survey of higher proportions of abdominal obesity among North American girls than boys. ${ }^{40} \mathrm{~A}$ striking contrast to these findings was reported by Albuquerque et a/ ${ }^{17}$ that registered significantly higher values in 6 - 12-year-old boys $(28.1 \%)$ than in girls of the same age $(19.4 \%)$.

A considerable proportion of normal and overweight children $(8.2 \%$ and $59.5 \%$, respectively) were abdominally obese and, thus, at risk of obesity associated comorbidities. ${ }^{10}$ Our findings are in agreement with the ones observed among Spanish children (aged 6 - 11) in which $9.6 \%$ of the normal weight and $67.5 \%$ of overweight children were abdominally obese. ${ }^{24}$ More recently, a study from Greece found that among normal weight and overweight children (aged 7 - 9) based on the IOTF definition, the prevalence of abdominal obesity was $3.4 \%-6.8 \%$ and $38.4 \%-49.1 \%$, respectively. ${ }^{37}$ In our study, abdominal obesity was more prominent in overweight girls than boys, which is not in line with previous findings. ${ }^{24,41}$ Also, we found that some obese children, particularly boys, were free of abdominal obesity which may beg the question if these children should be treated less 'aggressively' or in the same way as their abdominally obese peers.

Although BMI is widely considered as a simple anthropometric measure to assess obesity alongside evidence of good correlation between BMI with adverse metabolic outcomes, there are children with normal body weight and BMI who display abdominal obesity, which may be associated with other metabolic disturbances typical of obese persons. In fact, normal weight children with abdominal obesity appear to have a more adverse metabolic profile than overweight/obese children without abdominal obesity. ${ }^{42}$ Present findings suggest that abdominal obesity should be added to routine clinical practice, together with the measure of children's height and weight, in obese and non-obese children. WHtR is cheap, quick to measure and of easy calculation. However, current guidelines recommend using BMI for identifying childhood obesity and do not mention abdominal obesity as a screening tool. ${ }^{26}$

This study has several important strengths, including a large sample of children living in central Portugal. Also, the anthropometric measures were collected by the first author and a small group of well trained investigators. Nonetheless, our study has some limitations such as having no information on body composition, including percentage of body fat, and we did not evaluate the cardio-metabolic profile of our population and it is therefore unclear which index of obesity more accurately reflects cardiovascular risk. In addition, observations are limited to a sample of children living in central Portugal and generalizations of the results should thus be made with caution. Also, since this was a cross-sectional study, one cannot assess the incidence of obesity or follow the sample to assess BMI over time. Future studies should include a larger sample in order to obtain population-specific cut-off points for Portuguese children since two previous studies have reported different cut-offs associated with cardio-metabolic risk according to the population in which they were carried out. ${ }^{43,44}$ It should be interesting to observe possible differences (e.g., diet, physical activity, medical conditions) between children classified as obese by both the IOTF cut-off points and the $\mathrm{WHtR}$ and children classified as obese by only one indicator.

\section{CONCLUSION}

Overweight (including obesity) and abdominal obesity are highly prevalent in Portuguese children, which is a major public health issue. Nevertheless, comparing with previous studies, our results suggest a possible stabilization or plateau of the rates, following the pattern of other developed countries. A significant proportion of normal and overweight children was abdominally obese and can be considered at cardio-metabolic risk, but would not be identified as such using traditional screening methods. Our results indicate the need to incorporate waist circumference and WHtR into routine clinical practice together with the traditional BMI scale. By introducing this measure into clinical settings, more children would potentially be referred to programs, such as weight management, to receive help in improving their health. We conclude that WHtR is essential to track the amount of visceral fat and prevent the incidence of abdominal obesity which is known to be associated with cardiovascular diseases, that are major causes of death in Portugal.

\section{ACKNOWLEDGEMENTS}

The authors would like to thank all the schools, parents and children who participated in our study. The authors also acknowledge the support provided by the Portuguese Ministry of Education. 


\section{PROTECTION OF HUMANS AND ANIMALS}

The authors declare that the procedures were followed according to the regulations established by the Clinical Research and Ethics Committee and to the Helsinki Declaration of the World Medical Association.

\section{DATA CONFIDENTIALITY}

The authors declare having followed the protocols in use at their working center regarding patients' data publication. Informed consent was duly obtained from the patient.

\section{REFERENCES}

1. de Onis M, Blössner M, Borghi E. Global prevalence and trends of overweight and obesity among preschool children. Am J Clin Nutr. 2010;92:1257-64.

2. WHO. WHO | Obesity and overweight. Published 2016. [accessed 2016 Apr 30]. Available from: http://www.who.int/mediacentre/factsheets/ fs311/en/.

3. Padez C, Fernandes T, Mourão I, Moreira P, Rosado V. Prevalence of overweight and obesity in 7-9- year-old Portuguese children: Trends in body mass index from 1970-2002. Am J Hum Biol. 2004;16:670-8.

4. Gomes TN, Katzmarzyk PT, dos Santos FK, Souza M, Pereira S, Maia JA. Overweight and obesity in Portuguese children: prevalence and correlates. Int J Environ Res Public Health. 2014;11:11398-417.

5. Lobstein T, Jackson-Leach R, Moodie ML, Hall KD, Gortmaker SL, Swinburn BA, et al. Child and adolescent obesity: part of a bigger picture. Lancet. 2015;385:2510-20.

6. Lee CM, Huxley RR, Wildman RP, Woodward M. Indices of abdominal obesity are better discriminators of cardiovascular risk factors than BMI: a meta-analysis. J Clin Epidemiol. 2008;61:646-53.

7. Schmidt MD, Dwyer T, Magnussen CG, Venn AJ. Predictive associations between alternative measures of childhood adiposity and adult cardiometabolic health. Int J Obes. 2011;35:38-45.

8. Biro FM, Wien M. Childhood obesity and adult morbidities. Am J Clin Nutr. 2010;91:1499S-1505S.

9. Sanders RH, Han A, Baker JS, Cobley S. Childhood obesity and its physical and psychological co-morbidities: a systematic review of Australian children and adolescents. Eur J Pediatr. 2015;174:715-46.

10. Savva SC, Tornaritis M, Savva ME, Kourides Y, Panagi A, Silikiotou N, et al. Waist circumference and waist-to-height ratio are better predictors of cardiovascular disease risk factors in children than body mass index. Int J Obes. 2000;24:1453-8.

11. Kelishadi R, Mirmoghtadaee P, Najafi H, Keikha M. Systematic review on the association of abdominal obesity in children and adolescents with cardio-metabolic risk factors. J Res Med Sci. 2015;20:294-307.

12. Freedman DS, Khan LK, Serdula MK, Dietz WH, Srinivasan SR, Berenson GS. The relation of childhood BMI to adult adiposity: the Bogalusa Heart Study. Pediatrics. 2005;115:22-7.

13. Wijnhoven TM, van Raaij JM, Spinelli A, Rito Al, Hovengen R, Kunesova M, et al. WHO European Childhood Obesity Surveillance Initiative 2008: weight, height and body mass index in 6-9-year-old children. Pediatr Obes. 2013;8:79-97.

14. Rito Al, Paixão E, Carvalho MA, Ramos C. Childhood Obesity Surveillance Iniciative - COSI Portugal 2008. Lisboa: COSI; 2011.

15. Sardinha LB, Santos R, Vale S, Silva AM, Ferreira JP, Raimundo AM, et al. Prevalence of overweight and obesity among Portuguese youth: a study in a representative sample of 10-18-year-old children and adolescents. Int J Pediatr Obes. 2011;6:e124-8.

16. Rito A, Wijnhoven TM, Rutter H, Carvalho MA, Paixao E, Ramos $C$, et al. Prevalence of obesity among Portuguese children (6-8 years old) using three definition criteria: COSI Portugal, 2008. Pediatr Obes. 2012;7:41322.

17. Albuquerque D, Nóbrega C, Samouda H, Manco L. Assessment of obesity and abdominal obesity among Portuguese children. Acta Med Port. 2012;25:169-73.

18. de Onis M, Onyango AW, Borghi E, Siyam A, Nishida C, Siekmann J. Development of a WHO growth reference for school-aged children and adolescents. Bull World Health Organ. 2007;85:660-7.

19. Cole TJ, Lobstein T. Extended international (IOTF) body mass index cutoffs for thinness, overweight and obesity. Pediatr Obes. 2012;7:284-94.

20. Lopes HM de S. Diagnostic accuracy of CDC, IOTF and WHO criteria for obesity classification, in a Portuguese school-aged children population

\section{CONFLICTS OF INTEREST}

All authors report no conflict of interest.

\section{FUNDING SOURCES}

This work was supported by Fundação para a Ciência e Tecnologia (Foundation for Science and Technology) under grant SFRH/BD/90737/2012.

[Tese de Mestrado] Porto: ISP; 2012.

21. Garnett SP, Baur LA, Cowell CT. The prevalence of increased central adiposity in Australian school children 1985 to 2007. Obes Rev. 2011;12:887-96.

22. McCarthy HD, Jarrett KV, Emmett PM, Rogers I. Trends in waist circumferences in young British children: a comparative study. Int $\mathrm{J}$ Obes. 2005;29:157-62.

23. Bibiloni M del M, Pons A, Tur JA. Defining body fatness in adolescents: a proposal of the Afad-A classification. PLoS One. 2013;8:e55849.

24. Schröder H, Ribas L, Koebnick C, Funtikova A, Gomez SF, Fíto M, et al. Prevalence of abdominal obesity in Spanish children and adolescents. Do we need waist circumference measurements in pediatric practice? PLoS One. 2014;9:e87549.

25. Mokha JS, Srinivasan SR, Dasmahapatra P, Fernandez C, Chen W, $\mathrm{Xu} \mathrm{J}$, et al. Utility of waist-to-height ratio in assessing the status of central obesity and related cardiometabolic risk profile among normal weight and overweight/obese children: The Bogalusa Heart Study. BMC Pediatr. 2010;10:73.

26. US Preventive Services Task Force UPST, Barton M. Screening for obesity in children and adolescents: US Preventive Services Task Force recommendation statement. Pediatrics. 2010;125:361-7.

27. Ministério da Saúde. Consultas de Vigilância de Saúde Infantil E Juvenil - Actualização Das Curvas de Crescimento. Lisboa: MS; 2006.

28. Rodrigues D, Padez C, Machado-Rodrigues AM. Active parents, active children: The importance of parental organized physical activity in children's extracurricular sport participation. J Child Health Care. 2017:1-12.

29. Rodrigues D, Padez C, Machado-Rodrigues AM. Perceived psychological, cultural, and environmental barriers to sport in children living in urban and non-urban settings in the Midlands, Portugal. Sport Sci Health. 2017:1-7.

30. Pordata. Alunos matriculados nos ensinos pré-escolar, básico e secundário: total e por nível de ensino. Published 2016. [accessed 2016 Apr 12]. Available from: https://www.pordata.pt/Homepage.aspx

31. Schwandt P. Defining central adiposity in terms of clinical practice in children and adolescents. Int J Prev Med. 2011;2:1-2.

32. Cardoso HF, Padez C. Changes in height, weight, BMI and in the prevalence of obesity among 9- to 11-year-old affluent Portuguese schoolboys, between 1960 and 2000. Ann Hum Biol. 2008;35:624-38.

33. Padez C, Mourão I, Moreira P, Rosado V. Prevalence and risk factors for overweight and obesity in Portuguese children. Acta Paediatr. 2005;94:1550-7.

34. Bingham DD, Varela-Silva MI, Ferrão MM, Augusta G, Mourão MI, Nogueira $H$, et al. Socio-demographic and behavioral risk factors associated with the high prevalence of overweight and obesity in Portuguese children. Am J Hum Biol. 2013;25:733-42.

35. Wabitsch M, Moss A, Kromeyer-Hauschild K. Unexpected plateauing of childhood obesity rates in developed countries. BMC Med. 2014;12:17.

36. Mota J, Flores L, Flores L, Ribeiro JC, Santos MP. Relationship of single measures of cardiorespiratory fitness and obesity in young schoolchildren. Am J Hum Biol. 2006;18:335-41.

37. Hassapidou M, Tzotzas T, Makri E, Pagkalos I, Kaklamanos I, Kapantais $\mathrm{E}$, et al. Prevalence and geographic variation of abdominal obesity in 7and 9-year-old children in Greece; World Health Organization Childhood Obesity Surveillance Initiative 2010. BMC Public Health. 2017;17:126.

38. Sjöberg A, Moraeus L, Yngve A, Poortvliet E, Al-Ansari U, Lissner L. Overweight and obesity in a representative sample of schoolchildren exploring the urban-rural gradient in Sweden. Obes Rev. 2011;12.

39. Biehl A, Hovengen R, Grøholt EK, Hjelmesæth J, Strand BH, Meyer HE. Adiposity among children in Norway by urbanity and maternal education: 
a nationally representative study. BMC Public Health. 2013;13:842.

40. Li C, Ford ES, Mokdad AH, Cook S. Recent trends in waist circumference and waist-height ratio among US children and adolescents. Pediatrics. 2006;118:e1390-8.

41. Kromeyer-Hauschild K, Neuhauser H, Schaffrath Rosario A, Schienkiewitz A. Abdominal obesity in German adolescents defined by waist-to-height ratio and its association to elevated blood pressure: the KiGGS Study. Obes Facts. 2013;6:165-75.

42. Khoury M, Manlhiot $\mathrm{C}$, McCrindle BW. Role of the waist/height ratio in the cardiometabolic risk assessment of children classified by body mass index. J Am Coll Cardiol. 2013;62:742-51.

43. Elizondo-Montemayor L, Serrano-González M, Ugalde-Casas PA Bustamante-Careaga $\mathrm{H}$, Cuello-García C. Waist-to-height: cutoff matters in predicting metabolic syndrome in Mexican children. Metab Syndr Relat Disord. 2011;9:183-90.

44. Kruger HS, Faber M, Schutte AE, Ellis SM. A proposed cutoff point of waist-to-height ratio for metabolic risk in African township adolescents. Nutrition. 2013;29:502-7. 